\title{
Cytoskeletal Architecture of the Matrix Cell and Neuroblast in the Neural Tube of the Chick Embryo*
}

\author{
Takao Senda, Tomoko Hirabayashi, Keijiro Fukazawa and Hisao Fujita \\ Department of Anatomy, Osaka University Medical School, Suita, Japan
}

Received December 5, 1991

\begin{abstract}
Summary. Cytoskeletal architecture of the matrix cell and neuroblast in the wall of midbrain of 4-6 day-old chick embryos was examined by electron microscopy and immunohistochemistry. The matrix cell, the undifferentiated stem cell later producing neurons and glial cells in the central nervous system, is characterized ultrastructurally by abundant free ribosomes and a poorly developed cytomembrane system. A few microtubules running in random directions are observed in the matrix cell body. In the cell processes, microtubules are oriented longitudinally, and linked with each other by cross-bridges, presumably composed of microtububeassociated proteins (MAPs). The cell processes contain abundant cytoplasmic filaments including a large amount of actin filaments which adhere to the plasma membrane of junctional complexes located immediately below the inner surface of the neural tube.

In the neuroblast which has been differentiated from the matrix cell, the cytomembranous organelles, especially rough endoplasmic reticulum are markedly better developed than in the matrix cell; microtubules are more numerous in the cell body. The cell process contains many microtubules with cross-bridges and a few intermediate filaments, which are relatively characteristic of the cytoskeleton of the neuroblast.

Phalloidin-staining and immunohistochemistry showed that the neuroblast was richer in $\mathbf{F}$-actin, $\beta$-tubulin, MAP1, MAP2, tau, calspectin, and synapsin I than the matrix cell. As the matrix cell differentiates into the neuroblast, both the cytoskeletal and cytomembranous systems proved to develop features, characteristic of a neuron.
\end{abstract}

In the first stage of differentiation of the central nervous system, the neural tube is composed solely of matrix cells (Fig. 1a; FujiTA, 1960, 1963). The matrix cells are undifferentiated stem cells which later produce all of neurons and glias, though microglias have been considered to be derived from mesenchymal cells (BLOOM and FAWCETT, 1986). During the 5th day of incubation, neuroblasts, which are derived from the matrix cells, first appear in the peripheral zone outside of the layer composed of the matrix cells. The 6-day-old chick embryo clearly reveals the wall of the neural tube consisting of the matrix layer on the inside and the mantle layer on the outside (Fig. $1 b)$. The former is composed of the matrix cell bodies and their cytoplasmic processes, and the latter is of the neuroblast cell bodies, their cytoplasmic processes and the matrix cell processes extending from the matrix layer (Fig. $2 \mathrm{a}-\mathrm{c}$ ). The matrix cell is labelled with ${ }^{3} \mathrm{H}$-thymidine, while the neuroblast is not; this indicates the former is mitotically active while the latter inactive (FUJITA, 1963; FUJITA and FuJiTA, 1963). Afterwards, neuroblasts differentiate into all kinds of neurons in the central nervous system without mitosis and with morphological and functional specialization. Neuroblasts are destined to become neurons, and never differentiate into any other kinds of cells. Glial cells originate from the rest of the matrix cells which have not differentiated into neuroblasts.

Some significant ultrastructural changes during the differentiation from the matrix cell into the neuroblast have been reported. In the neuroblast, the cytomembrane system is more developed than in the matrix cell; especially, rough endoplasmic reticulum - which is hardly seen in the matrix cell-is frequently observed in the neuroblast (Fig. 2a, b; FuJiTA and FujiTA, 1963). The subcellular structures in the neuroblast are therefore considered to be developing toward those of the neuron.

The neuron is a highly-differentiated cell both morphologically and functionally. It has recently

*This study was supported in part by grants from the Research Fund of the Ministry of Education, Science, and Culture, Japan. 
been clarified that the cytoskeletal system is involved in morphogenesis and in the display of functions of the neuron (HiroKAWA, 1988, 1991). Though changes in the cytoskeletal architecture during differentiation of the matrix cell into the neuroblast present an interesting problem, no study from this point of view has yet been reported.

The present study was planned to examine the cytoskeletal architecture in the matrix cell and neuroblast of the chick embryo using both electron microscopy including thin sectioning, quick-freezedeep-etching and quick-freeze-substitution, and immunohistochemistry in order to reveal changes in the cytoskeletal architecture as the matrix cell differentiates into the neuroblast.

\section{MATERIALS AND METHODS}

About 50 embryos of White Leghorn domestic fowl were used for this study. Midbrains, being easiest to resect out of the neural tube, were taken from 4,5 and 6 day-old embryos, and processed as described below.

\section{Conventional light microscopy}

The midbrains were fixed with $2 \%$ glutaraldehyde in $0.075 \mathrm{M}$ cacodylate buffer ( $\mathrm{pH} 7.2$ ) for $2 \mathrm{~h}$. After washing with the buffer, the specimens were dehydrated with ethanol, and embedded in JB-4 resin (Polyscience). Sections were stained with hematoxylin-eosin, and examined with a Zeiss Photomicroscope III.

\section{Conventional thin section electron microscopy}

The midbrains, cut into small pieces, were fixed with $2 \%$ glutaraldehyde in $0.075 \mathrm{M}$ cacodylate buffer $(\mathrm{pH}$ 7.2) for $2 \mathrm{~h}$, and subsequently with $1 \% \mathrm{O}_{\mathrm{s}} \mathrm{O}_{4}$ in the same buffer for $1 \mathrm{~h}$.

After block-staining with uranyl acetate solution, the specimens were dehydrated with ethanol, and embedded in Epon epoxy resin. Ultrathin sections cut with a Reichert-Nissei Ultracut M ultramicrotome were stained with uranyl acetate and lead citrate, and examined with a JEOL 1200 EX electron microscope.
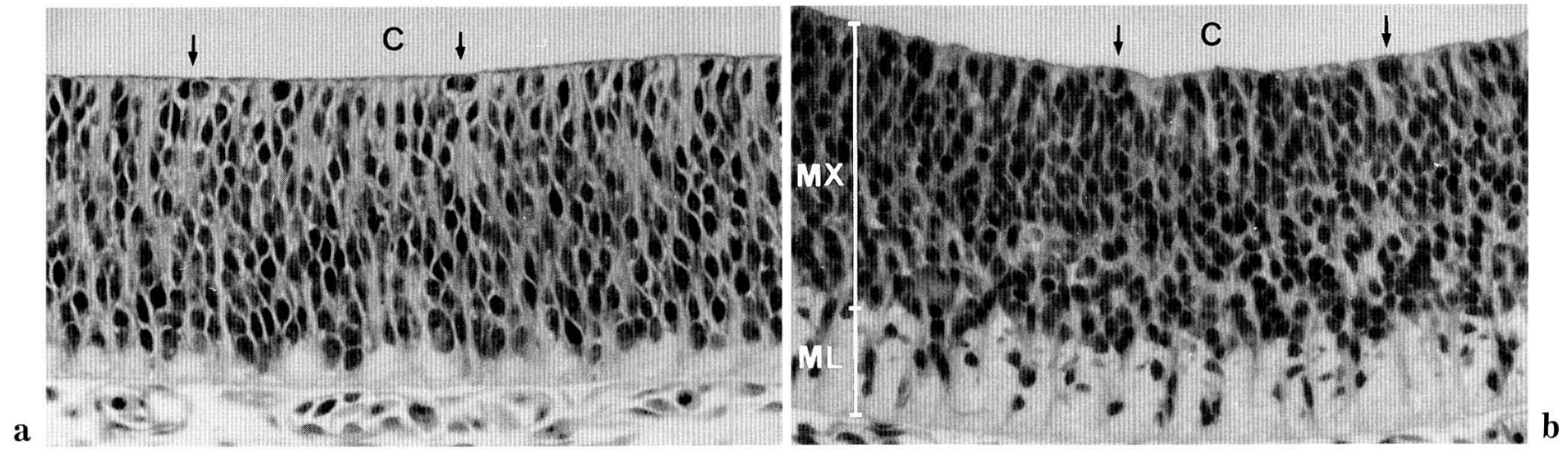

Fig. 1. Hematoxylin-eosin stained midbrains of chick embryos. The midbrain of the 4-day-old embryo is composed solely of matrix cells (a). The midbrain of the 6-day-old embryo consists of the matrix layer $(M X)$ composed of matrix cells and the mantle layer $(M L)$ of neuroblasts (b). Mitotic figures of the matrix cells (arrows) occur in the innermost region facing the central canal $(C)$. a, b: $\times 350$

Fig. 2. Electron microscopic images of the midbrain from a 6-day-old chick embryo, which is cut perpendicularly to the surfaces of the neural tube. a. A part of the matrix layer, which is composed solely of matrix cells. The matrix cell is spindle-shaped with cytoplasmic processes extending perpendicularly to the surface of the neural tube. Scanty cytoplasm of the matrix cell is characterized by abundant free ribosomes and a poorlydeveloped cytomembrane system. $\times 6,000$. b and $\mathbf{c}$. Parts of the mantle layer. The mantle layer consisits of neuroblast cell bodies, their cytoplasmic processes $(P)$, and processes extending from matrix cell bodies $(P M)$. The neuroblast contains abundant free ribosomes, and membranous organelles better developed than in the matrix cell, such as mitochondria, Golgi apparatus $(G)$ and rough endoplasmic reticulum $(R)$. A cytoplasmic process $(P$ in $\mathbf{c})$ of the neuroblast extending toward the outside of the neural tube turns in direction parallel to the surface of the neural tube (arrow). b: $\times 11,000, c: \times 6,000$ 

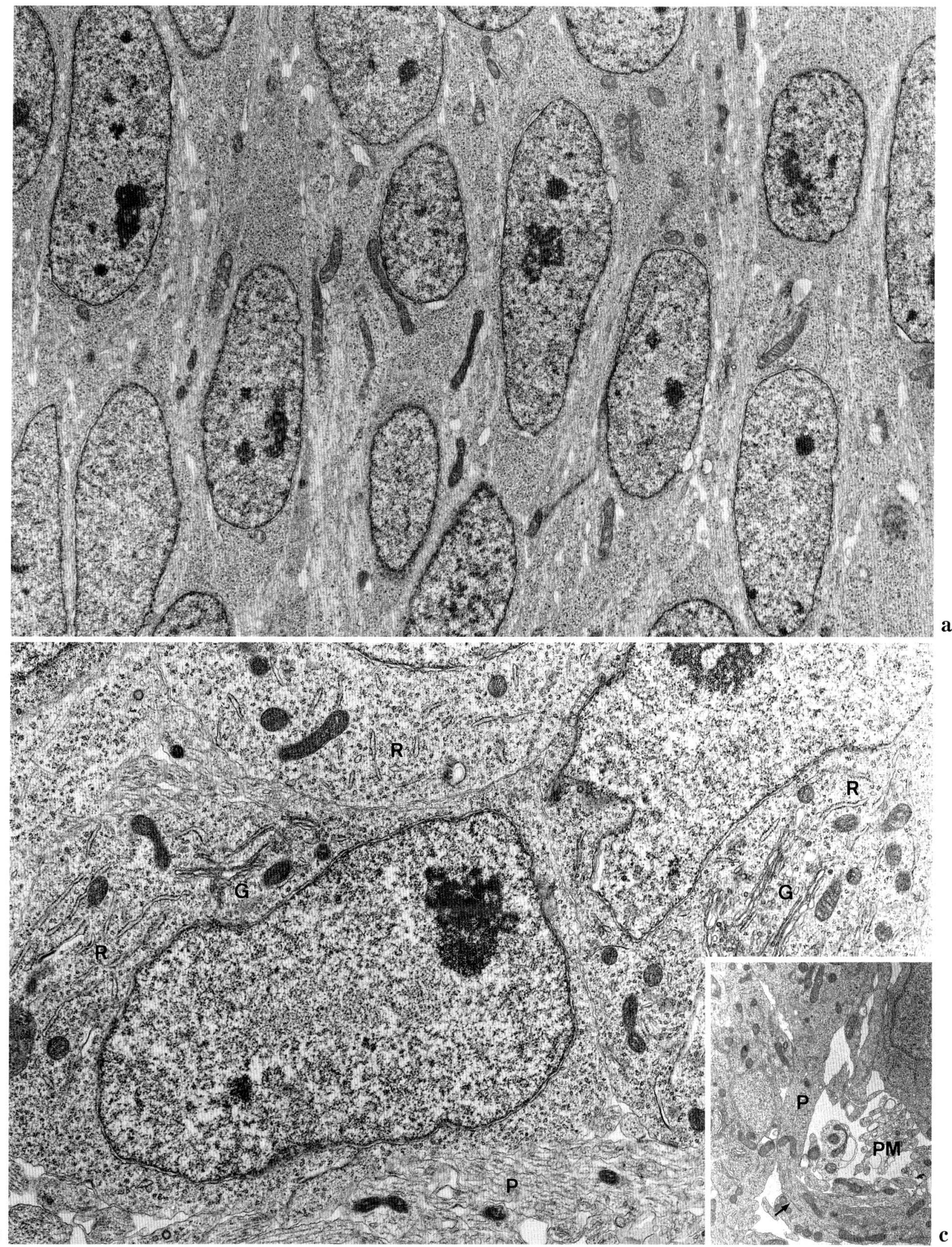

Fig. 2. Legend on the opposite page. 


\section{Quick-freeze, deep-etching electron microscopy}

Fresh or glutaraldehyde-fixed midbrains were quickly frozen using a Polaron quick-freezing apparatus Slammer cooled with liquid helium as previously described (SENDA and FujiTA, 1987). The frozen tissues were fractured at $<1 \times 10^{-6}$ Torr at $-125^{\circ} \mathrm{C}$, and their surfaces were deeply-etched at $-100^{\circ} \mathrm{C}$ for 3 min in a JEOL JFD 9000 freeze-etching apparatus. Replicas of the fractured surfaces were made by rotary shadowing with platinum and carbon. The tissues under the replicas were dissolved away with household bleach at room temperature. The liberated replicas were washed with distilled water, picked up on copper grids, and examined with an electron microscope. Photographs of the deep-etching replicas were printed in negative image.

\section{Quick-freeze-substitution method}

Luminal surfaces of fresh midbrains were slammed against the copper block on the quick-freezing apparatus. The frozen tissues were incubated in $1 \% \mathrm{O}_{\mathrm{s}} \mathrm{O}_{4}$ in acetone at $-80^{\circ} \mathrm{C}$ for $48 \mathrm{~h}$, at $-20^{\circ} \mathrm{C}$ for $2 \mathrm{~h}$, at $4^{\circ} \mathrm{C}$ for $2 \mathrm{~h}$, and then at room temperature for $2 \mathrm{~h}$. The specimens were washed with pure acetone and ethanol, and block-stained with $2 \%$ uranyl acetate in ethanol for $1 \mathrm{~h}$. After washing with ethanol, the specimens were embedded in Epon epoxy resin. Sections were cut at $10 \mu \mathrm{m}$ parallel to the slammed surface, stained with uranyl acetate and lead citrate, and examined with an electron microscope.

\section{Phalloidin staining for F-actin}

Midbrains of the 6-day-old embryos were fixed with $3 \%$ paraformaldehyde in $0.1 \mathrm{M}$ phosphate buffer $(\mathrm{pH}$ 7.2) at $4^{\circ} \mathrm{C}$ for $2 \mathrm{~h}$. The specimens were washed thoroughly with $10 \%$ sucrose in phosphate-buffered saline (PBS), embedded in OCT compound, and frozen. Frozen sections cut on a Microm cryostat HM 500 were mounted on albumin-coated slide glasses. The sections were incubated in $50 \mu \mathrm{g} / \mathrm{ml}$ fluorescein isothiocyanate (FITC)-labeled phalloidin (Sigma) in PBS at room temperature for $1 \mathrm{~h}$, washed with PBS, and examined with a Nikon Fluophoto fluorescence microscope.

\section{Immunohistochemistry}

The frozen sections described above were incubated in monoclonal anti- $\beta$-tubulin (Sigma), monoclonal anti-microtubule associated protein (MAP) 1 (Biomaker), polyclonal rabbit anti- MAP 2 and tau (Sigma), polyclonal rabbit anti-calspectin (SOBUE et al., 1982, 1987; ISHIMURA et al., 1987), polyclonal rabbit antisynapsin I (KANDA et al., 1986; OKABE and SoBUE, 1987) antibodies diluted at $1: 200-1000$ in PBS at $4^{\circ} \mathrm{C}$ for $48 \mathrm{~h}$. After washing with PBS, the sections were incubated in FITC-labelled anti-mouse IgG (Miles Scientific) for the monoclonal antibodies or FITClabelled anti-rabbit IgG (Seikagaku Kogyo) for the polyclonal antibodies diluted at 1: 100 in PBS at room temperature for $2 \mathrm{~h}$, washed with PBS, and examined with a fluorescence microscope.

\section{RESULTS}

\section{Orientation and fine structure of the matrix cell and neuroblast}

As reported by FujiTA (1963), and FujiTA and FujiTA (1963), the wall of the midbrain of 4-day-old chick embryos and the matrix layer of the 5 and 6 -day-old embryos are composed of only one kind of cell, called the matrix cell (Fig. 1a, b). The matrix cell in the 4 , 5 and 6-day-old embryos exhibits the same features. This cell is spindle-shaped with long cytoplasmic processes extending towards both the inner and outer surfaces of the neural tube (Fig. 2a). The cell body contains an oval nucleus and scanty cytoplasm filled with abundant free ribosomes. As for membrane organelles, some mitochondria, small vesicles, and moderately developed Golgi apparatus are scattered in the cytoplasm, while endoplasmic reticulum is hardly seen. In general, the matrix cell is an undifferentiated cell characterized by abundant free ribosomes and a poorly developed cytomembrane system.

In 5-day-old embryos, neuroblasts which have been derived from the matrix cells appear for the first time in the peripheral zone outside of the matrix layer

\footnotetext{
Fig. 3. Thin section (a, c) and quick-freeze-deep-etch (b, d, e) electron microscopic images of cell bodies (a, b) and cytoplasmic processes (c, d, e) of matrix cells. The cytoplasm of the matrix cell is filled with abundant free ribosomes, but is poor in membranous organelles (a). A few microtubules are seen in the cytoplasm of the cell body. (arrowheads in a, b). Numerous fine filaments (arrows in b) with branchings and anastomoses form complicated networks in the cytoplasm of the cell body. In the cytoplasmic process, microtubules are oriented longitudinally (c, d, e). Many cross-bridges span between microtubules (arrows in d). a: $\times 45,000, \mathrm{~b}: \times 119,000$, c: $\times 44,000, \mathrm{~d}: \times 73,000$, e: $\times 62,000$
} 


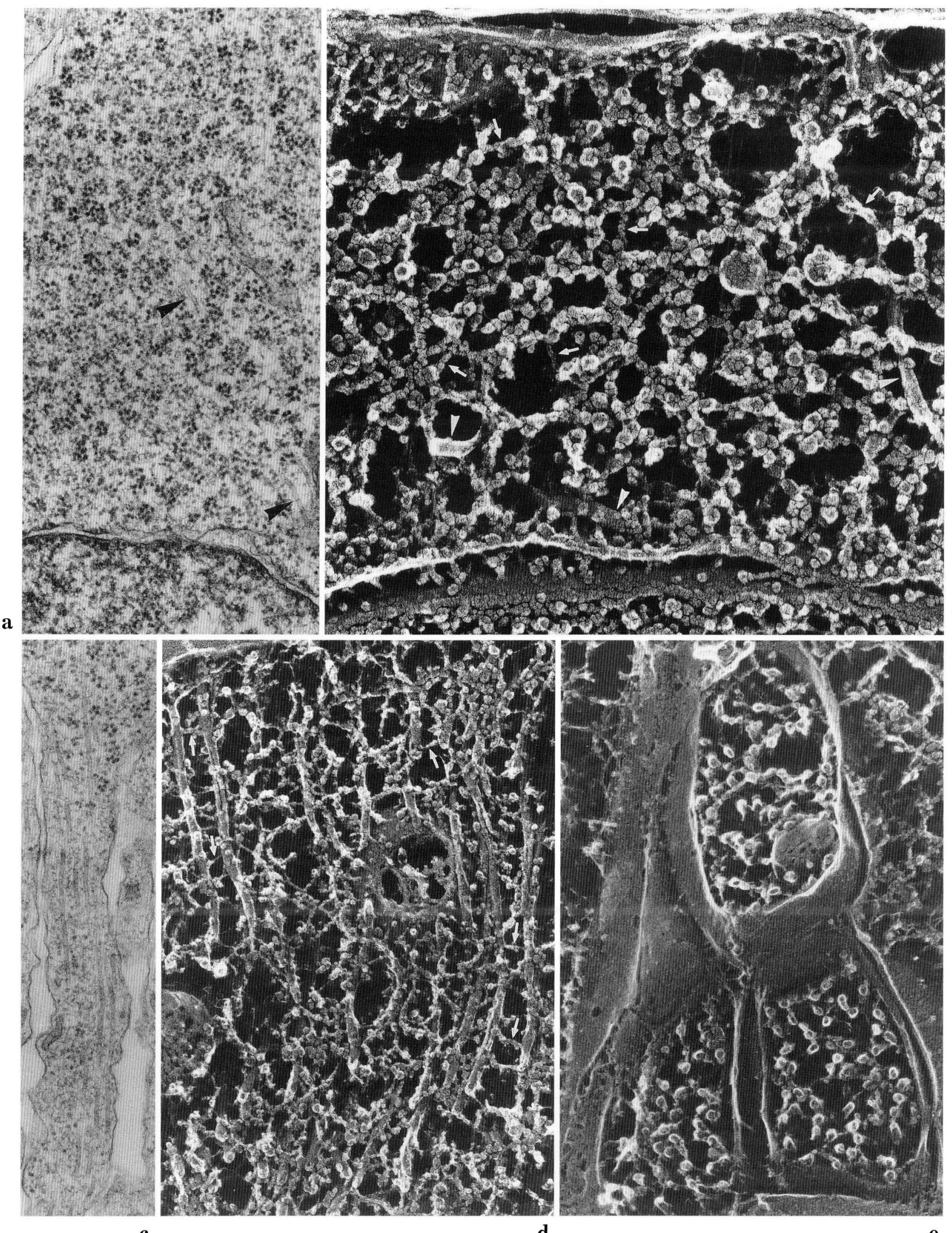

Fig. 3. Legend on the opposite page. 


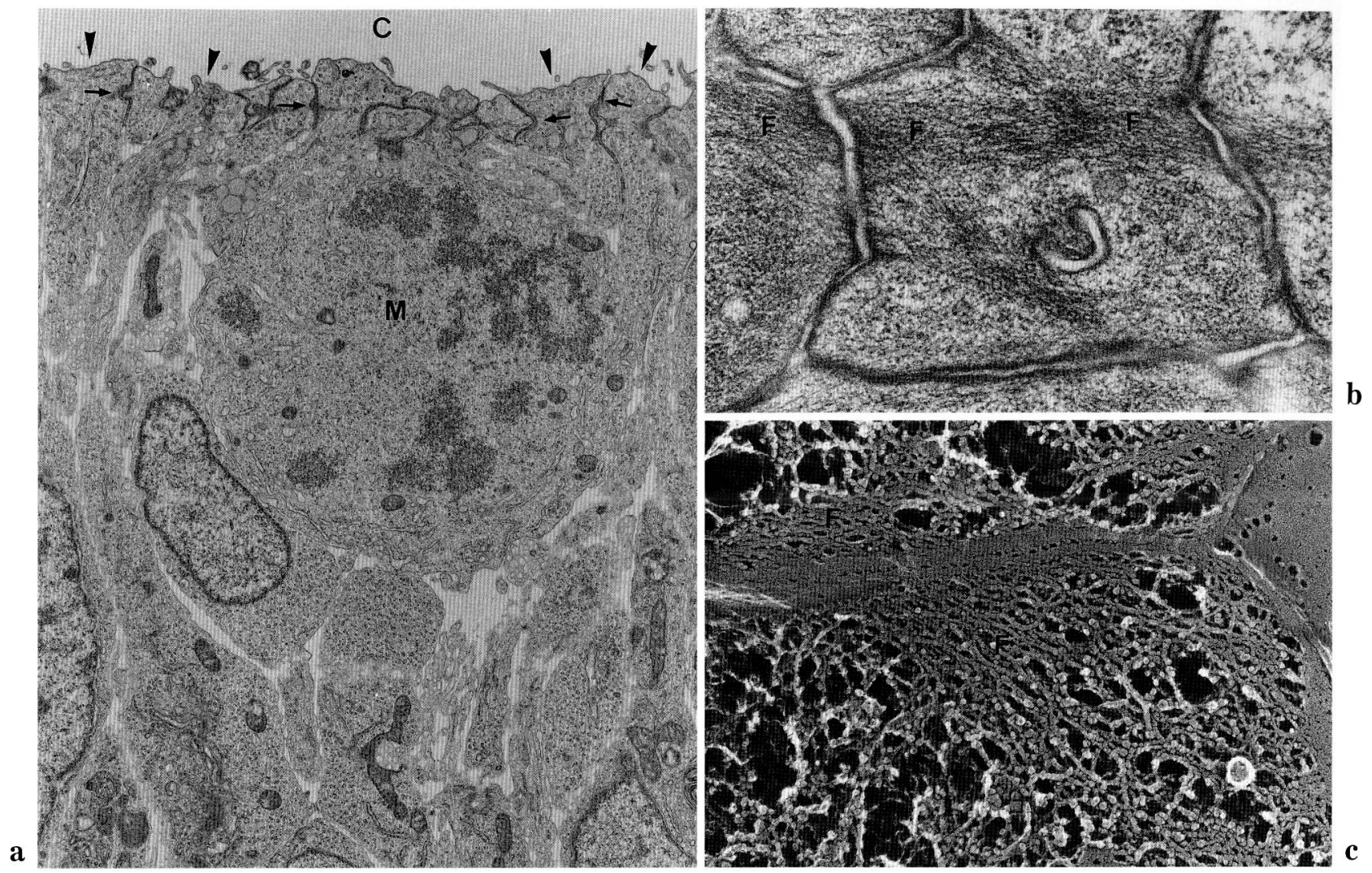

Fig. 4. Parts of the region under the inner surface of the neural tube. a. A conventional electron microscopic image of a perpendicular section. Mitosis of the matrix cell $(M)$ occurs in the region under the inner surface of the neural tube. Inner ends of the cytoplasmic processes (arrowheads) extending from the matrix cell body localized deeper in the matrix layer always face the central canal $(C)$. These processes and the matrix cell in mitosis are sealed by junctional complexes close to the inner surface of the neural tube (arrows). $\times 7,500$. $\mathbf{b}$ and c. Quick-freeze-substitution (b) and quick-freeze-deep-etching (c) images of planes cut or fractured beneath the inner surface of the neural tube in parallel with it. Abundant cytoplasmic filaments $(F)$ adhere to the inside of the plasma membrane of the junctional complexes in the cytoplasmic processes of the matrix cell. $b: \times 40,000$, c: $\times 33,000$

composed of the matrix cells. In 6-day-old embryos, the neuroblast cell bodies, their cytoplasmic processes, and the matrix cell processes form the mantle layer outside of the matrix layer (Fig. 1b). The neuroblast is polygonal or irregular in shape with cytoplasmic processes (Fig. 2b, c). Its cell body contains a variously shaped nucleus and a larger quantity of cytoplasm than that of the matrix cell. The cytoplasm is filled with abundant free ribosomes as seen in the matrix cell. The cytomembrane system is much more developed than in the matrix cell (Figs. 2b, 5a, b, d). Mitochondria and small vesicles increase in number, and the Golgi apparatus is more mature as compared with those in the matrix cell. As reported by Fujita and Fujita (1963), the most noticeable characteristic of the neuroblast is a distinct development of rough endoplasmic reticulum, which is hard- ly seen in the matrix cell. Some membrane organelles, such as mitochondria and small vesicles, are observed also in the cytoplasmic processes of the neuroblast. Most of the cytoplasmic processes of the neuroblast extend either horizontally or perpendicularly to the surface of the neural tube. This is due to thier bending at right angles on their extension (Figs. 2c, 5d).

As reported by FujITA (1963), mitosis of the matrix cell occurs only in the inner most region of the matrix layer where the matrix cell faces the central canal (Figs. 1, 4a). The matrix cell in mitosis is spherical in shape, and its cytoplasmic processes are withdrawn. Around the spherical matrix cell in mitosis, many cytoplasmic processes extending from the cell body of matrix cells localized deeper in the matrix layer are oriented perpendicularly to the 
a
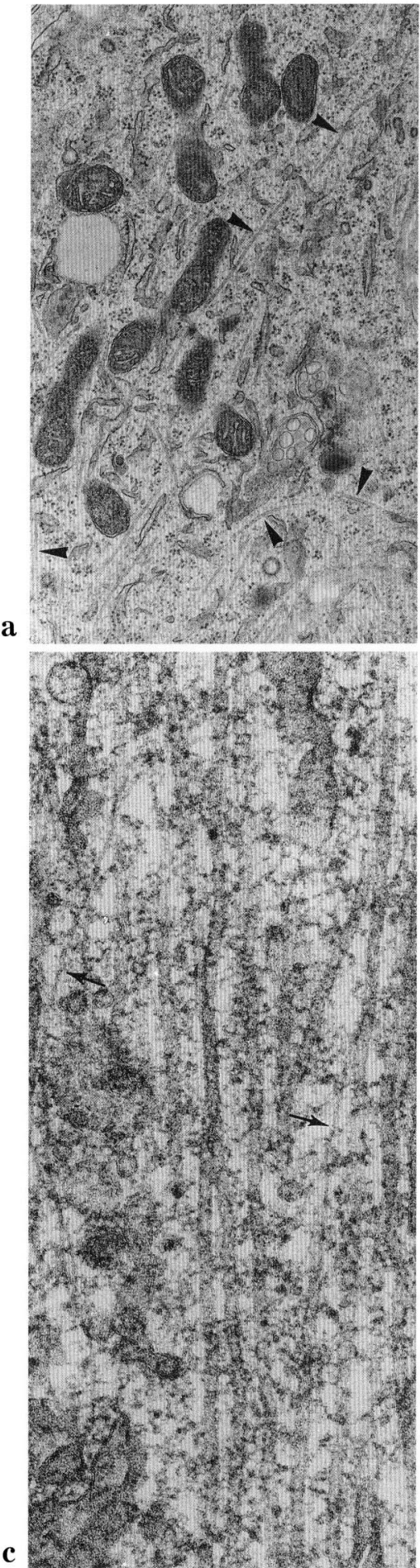
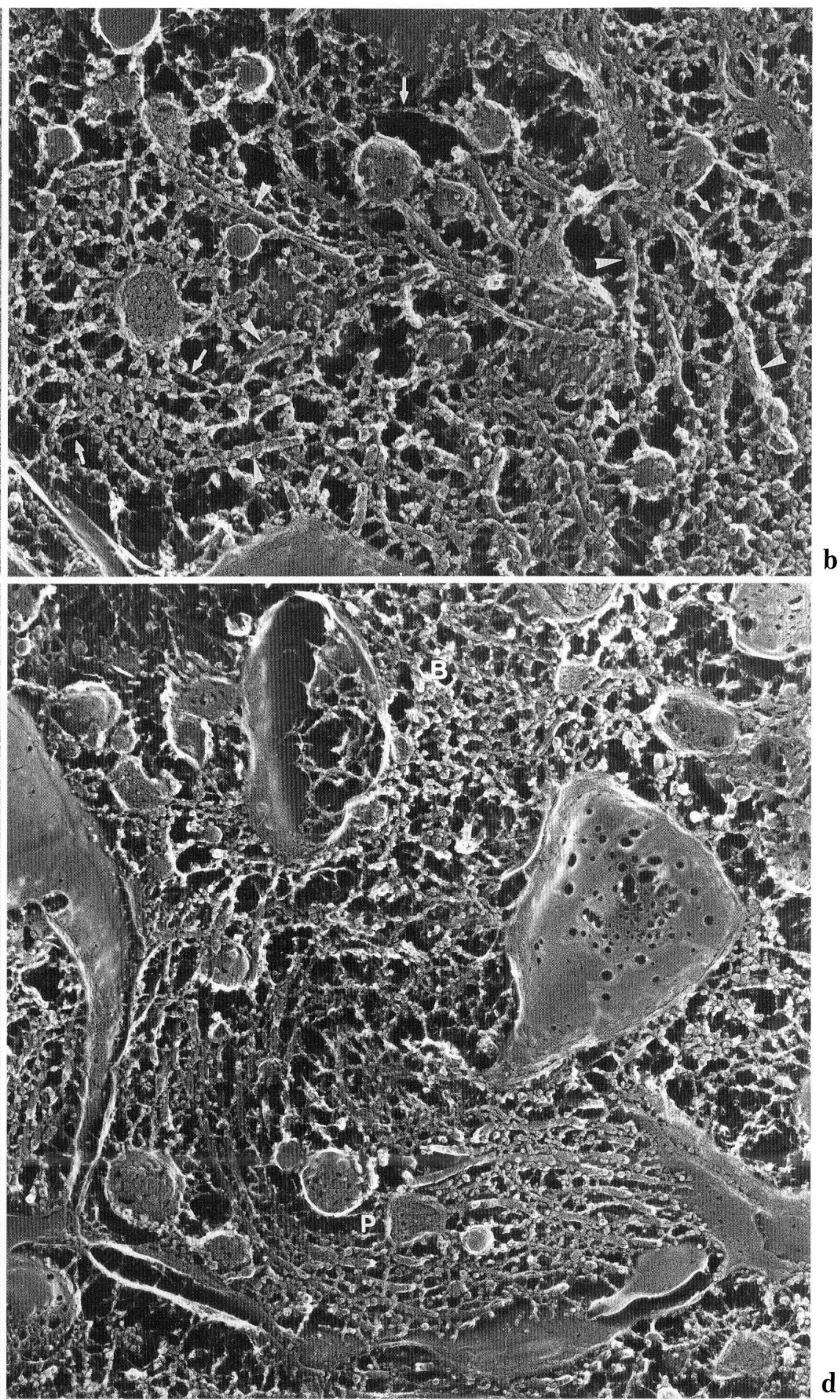

Fig. 5. Thin section (a, c) and quick-freeze-deep-etching (b, d) images of the cell body (a, b, $B$ in $\mathbf{d})$ and cytoplasmic process (c, $P$ in $\mathbf{d}$ ) of the neuroblast. $\mathbf{a}$ and $\mathbf{b}$ Many microtubules running in random directions (arowheads) are seen in the neuroblast cell body. Numerous fine filaments (arrows in b) with frequent branchings and anastomoses form networks in the cytoplasm. $\mathrm{a}: \times 17,000, \mathrm{~b}: \times 50,000$. $\mathbf{c}$ and $\mathbf{d}$ Many microtubules and some intermediate filaments (arrows in c) are longitudinally oriented in the cytoplasmic process of the neuroblast. Many cross-bridges link microtubules in the cytoplasmic process. Note that the cytoplasmic process $(P)$ extending perpendicularly from the cell body turns in a horizontal direction (d). c: $\times 80,000, \mathrm{~d}: \times 36,000$ 
a
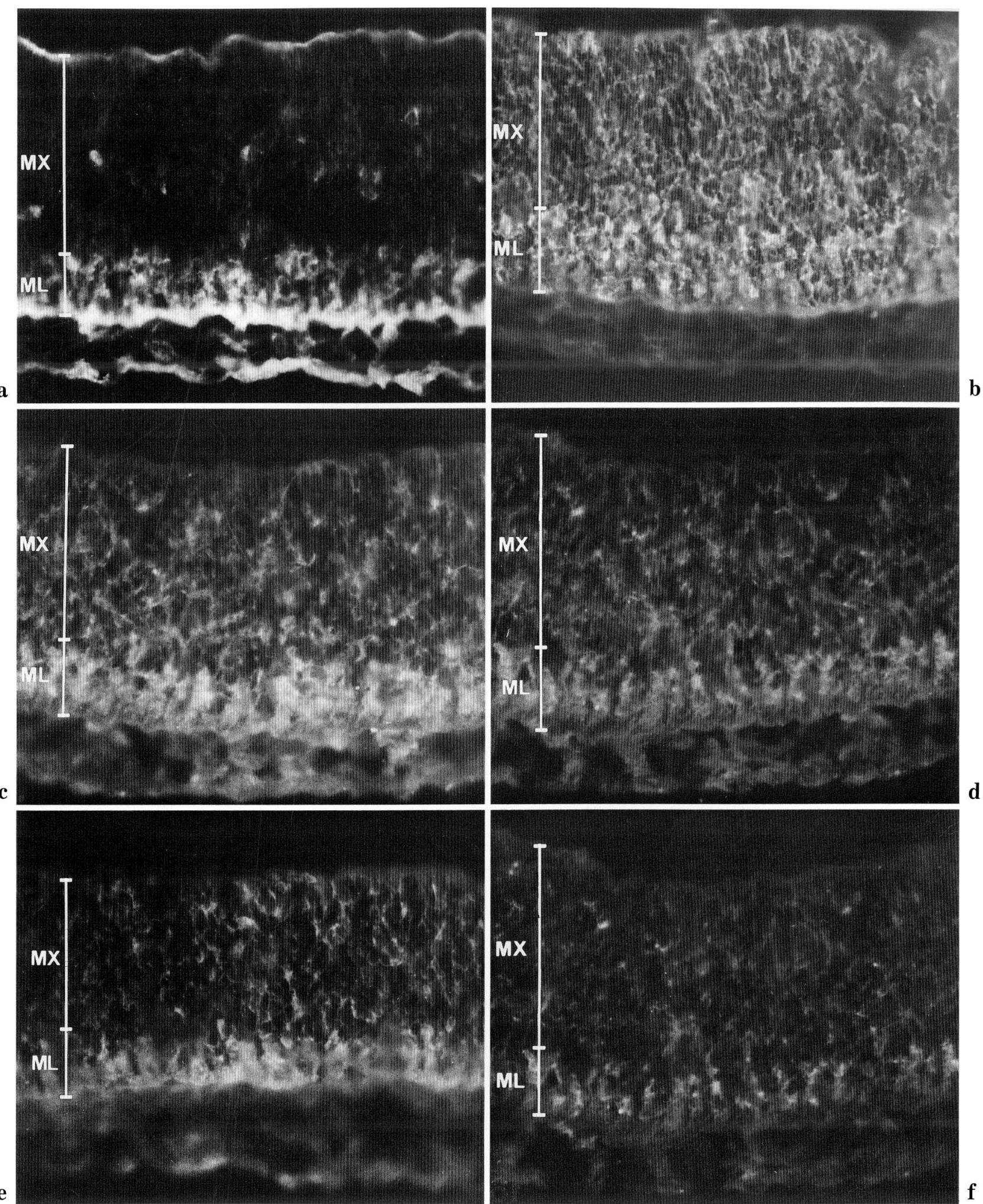

Fig. 6. Legend on the opposite page. 
inner surface of the neural tube (Fig. 4a). The inner ends of these processes always face the central canal. The matrix cell in mitosis and these processes are sealed by junctional complexes closely under the inner surface (Fig. $4 \mathrm{a}-\mathrm{c}$ ). Mitotic figures of the neuroblasts are never seen in the mantle layer.

\section{Cytoskeletal architecture of the matrix cell}

In the cytoplasm of the matrix cell body, a few microtubules, $25 \mathrm{~nm}$ in diameter, run in random directions (Fig. 3a, b). Quick-freeze, deep-etching electron microscopy revealed that a number of fine filaments, $5-15 \mathrm{~nm}$ in diameter, with frequent branching and anastomoses form complicated networks in the cytoplasm (Fig. 3b). Some of these filaments link with the plasma membrane, the outer leaflet of the nuclear membrane and the membranes of such cell organelles as mitochondria, Golgi apparatus and small vesicles.

In the cytoplasmic process of the matrix cell, several microtubules are oriented longitudinally (Fig. $3 \mathrm{c}-\mathrm{e})$. Many cross-bridges, $10-60 \mathrm{~nm}$ in length, can be recognized between adjacent microtubules (Fig. 3d). Among these cross-bridges, some are straight without branches or anastomoses, and others are reticular with them. Intermediate filaments are very few both in the cell body and processes of the matrix cell.

Abundant cytoplasmic filaments with a diameter of 8-15 $\mathrm{nm}$ join to the inside of the plasma membrane of the cytoplasmic processes under the inner surface of the neural tube, where these processes are sealed together by the junctional complexes (Fig. 4b, c). As phalloidin-staining shows abundant filaments located immediately beneath the inner surface of the neural tube (Fig. 6a), these $8-15 \mathrm{~nm}$ filaments are proved to contain a large amount of F-actin (actin filaments). Other parts of the matrix layer are not stained by phalloidin.

Immunohistochemistry demonstrates that $\beta$-tubulin, MAP1, MAP2, tau and calspectin are positive, where as synapsin I is hardly recognizable in both the matrix cell bodies and processes (Fig. 6b-f). The same immunohistochemical results were obtained in the 4, 5, and 6-day-old embryos. The intensities of all these reactions were markedly weaker than those in the neuroblast as mentioned below.

\section{Cytoskeletal architecture of the neuroblast}

In the neuroblast of the 6-day-old embryos, numerous microtubules running in random direction are observed in the cytoplasm of the cell body (Fig. 5a, b). A few intermediate filaments are also seen. Deep-etch electron microscopy demonstrated reticular networks formed of numerous fine filaments with frequent branchings and anastomoses in the cytoplasm of the cell body (Fig. 5b, d). Many filaments are associated with the plasma membrane, the outer leaflet of the nuclear envelope, and the membranes of such cell organelles as mitochondria, endoplasmic reticulum, Golgi apparatus and small vesicles. In the cytoplasmic processes, many microtubules are longitudinally oriented, and many cross-bridges connect between adjacent microtubules (Fig. 5 c, d). Some intermediate filaments run parallel to the microtubules (Fig. 5c). Intermediate filaments are noticeably more frequent in the neuroblast than in the matrix cell.

The neuroblasts in the mantle layer are intensely stained by FITC-phalloidin (Fig. 6a). Immunoreactivities against anti- $\beta$ - tubulin, MAP 1, MAP 2, tau, calspectin, and synapsin I antibodies are stronger in the neuroblast than in the matrix cell (Fig. 6b-f).

\section{DISCUSSION}

In the present study, cytoskeletal architectures in matrix cells and neuroblasts which compose the neural tube of the chick embryo were examined using electron microscopy and immunohistochemistry. The cytoskeletal system as well as the membranous organelles were proved to develop as the matrix cell differentiates into the neuroblast.

The matrix cell is a stem cell for all the neurons and most neuroglias. The neuroblast is an abvanced type on its differentiation toward the neuron. The matrix cell is heavily labelled by ${ }^{3} \mathrm{H}$-thymidine, while the neuroblast does not take it at all (FUJITA, 1963; FUjiTA and FujiTA, 1963). The former thus possesses mitotic activity, while the latter has lost it. The previous (FUJITA and FuJiTA, 1963) and present study demonstrated clear differences in fine structure between both cells. The matrix cell is characterized by abundant free ribosomes and a poorly developed

Fig. 6. Demonstration of F-actin by FITC-phalloidin staining (a), and of $\beta$-tubulin (b), MAP1 (c), MAP 2 and tau (d) calspectin (e), and synapsin I (f) by immunohistochemistry in the wall of the 6-day-old chick embryo midbrain. a. F-actin is localized in the region under the inner surface of the neural tube, and in neuroblasts in the mantle layer $(M L)$. b-e, $\beta$-Tubulin, MAP1, MAP 2, tau, and calspectin are localized more densely in the neuroblast in the mantle layer $(M L)$ than in the matrix cell in the matrix alyer $(M X)$. $\mathbf{f}$. Synapsin I is hardly detected in the matrix later $(M X)$, while it is positive in the neuroblast in the mantle layer $(M L) . \mathrm{a}-\mathrm{f}: \times 450$ 
cytomembrane system, while the neuroblast shows better developed membranous organelles such as mitochondria, Golgi apparatus, and the rough endoplasmic reticulum that is hardly seen in the matrix cell. This change is accounted for by that at the stage of the neuroblast, the cytomembrane system of the matrix cell is developing toward that of the neuron.

We are interested in the changes of the cytoskeletal system which occur during the differentiation from the matrix cell to the neuroblast, since it is known to take a leading role in morphogenesis of the neuron. In the present study, it was shown that microtubules were oriented longitudinally in the processes of the matrix cell, and that many crossbridges connect between the adjacent microtubules. Since MAP1, MAP 2 and tau have been demonstrated to be localized in the matrix cell body and its processes, these cross-bridges are considered to be composed of MAPs. It is well known that in the axon and dendrites of the neuron, microtubules and neurofilaments are arranged longitudinally, and cross-bridges composed of MAP1, MAP2A, and tau interlink the microtubules and the microtubules and neurofilaments (HIROKAWA et al., 1985, 1988; SHIOMURA and HIROKAWA, 1987). It is therefore suggested that the cytoskeletal architecture in the axon and dendrites of a neuron has essentially been established already in the cytoplasmic process of the matrix cell, though neurofilaments have not yet appeared. Microtubules distributed in the cell body are more frequently observed in the neuroblast than in the matrix cell. This is supported by the result of immunohistochemistry that the positive reaction against anti- $\beta$ tubulin antibody is stronger in the neuroblast than in the matrix cell.

Very few intermediate filaments are seen in the matrix cell, while a few are seen in the neuroblast. The chemical nature of these intermediate filaments is unknown.

FITC-phalloidin staining revealed the localization of abundant $\mathrm{F}$-actin in the region close to the inner aspect of the neural tube. In this region, a large number of cytoplasmic filaments are associated with the inside of the plasma membrane of the junctional comlexes between the adjacent processes of the matrix cells. Quite a few actin filaments are, therefore, contained among these cytoplasmic filaments. Since the abundant filaments containing numerous actin filaments reinforce the junctional complexes, the cytoplasmic processes can not be detached from the inner surface of the central canal in spite of the movement of the matrix cell due to its cell cycle, which has been shown by SAUER (1935) and FUJITA (1963). Strong staining of the neuroblast by FITC- phalloidin indicates that the fine filaments revealed in the neuroblast cell body by deep-etch electron microscopy contain many actin filaments.

Calspectin (fodrin) is one of the membrane-associated proteins in the neuron (LEVINE and WILLARD, 1981). This protein has been reported to be associated also with microtubules in axons and dendrites (Shimo-OKA and ATsumi, 1986). In the present study, calspectin is detected in the matrix cell bodies and their processes. In the neuroblast, a stronger reactivity for calspectin is recognized than in the matrix cell.

Synapsin I is a synaptic vesicle-associated protein in the nerve terminal, and is thought to relate with transmitter release triggered by $\mathrm{Ca}^{2+}$ influx $(\mathrm{DE}$ CAMilli et al., 1983a, b). Synapsin I is hardly recognized in the matrix cell bodies and their processes. This fact well coincides with the fact that synapses and synaptic vesicles, which are essential structures for chemical transmission, are not yet developed in the matrix cell.

In general, the cytoskeleton in the neuroblast is obviously better developed than in the matrix cell. It is concluded that cytoskeletal as well as cytomembranous systems such as mitochondria, rough endoplasmic reticulum, Golg apparatus, and small vesicles are developing toward those of a neuron during the differentiation from the matrix cell into a neuroblast.

Acknowledgements. We wish to express our hearty thanks to Prof. Kenji SoBuE, Department of Neurobio chemistry, Osaka University Medical School, for the anticalspectin and anti-synapsin I antibodies.

\section{REFERENCES}

Bloom, W. and D. W. Fawcett: Neuroglial cells. In: A textbook of histology. W. B. Saunders Comp., Philadelphia, 1986 (p. 345-347).

De Camilli, P., R. Cameron and P. Greengard: Synapsin I (protein I), a nerve terminal-specific phosphoprotein. I. Its general distribution in synapses of the central and peripheral nervous system demonstrated by immunofluorescence in frozen and plastic sections. J. Cell Biol. 96: 1337-1354 (1983a).

De Camilli, P., S. M. Harris Jr., W. B. Huttner and P. GREENGARD: Synapsin I (protein I), a nerve terminalspecific phosphoprotein. II. Its specific association with synaptic vesicles demonstrated by immunocytochemistry in agarose-embedded synaptosomes. J. Cell Biol. 96: 1355-1373 (1983b).

Fujita, H. and S. Fujita: Electron microscopic studies on neuroblast differentiation in the central nervous system of domestic fowl. Z. Zellforsch. 60: 463-478 (1963). 
Fujita, S.: Mitotic pattern and histogenesis of the central nervous system. Nature 185: 702-703 (1960).

- : The matrix cell and cytogenesis in the developing central nervous system. J. Comp. Neurol. 120: 37-42 (1963).

Hirokawa, N.: Interactions between cytoskeletal polymers in neurons: quick-freeze deep-etch and immunocytochemical studies. Neurol. Neurobiol. 37: 285-306 (1988).

-: Molecular architecture and dynamics of the neuronal cytoskeleton. In: (ed. by) R. D. BuRGOYNE: The neuronal cytoskeleton. Wiley-Liss Inc., New York, 1991 (p. 5-74).

Hirokawa, N., G. S. Bloom and R. B. Vallee: Cytoskeletal architecture and immunocytochemical localization of microtubule-associated proteins in regions of axons associated with rapid axonal transport: the $\beta$, $\beta^{\prime}$-iminodipropionitrile-intoxicated axon as a model system. J. Cell Biol. 101: 227-239 (1985).

Hirokawa, N., Y. Shiomura and S. OKabe: Tau proteins: the molecular structure and mode of binding on microtubules. J. Cell Biol. 107: 1449-1459 (1988).

Ishimura, K., T. Senda, K. Kitajima, H. Fujita, Y. FuJIo and K. Sobue: Immunocytochemical localization of calspectin (a non-erythroid spectrin-like protein) in thyroid glands of normal and TSH-treated rats. Histochemistry 86: 537-539 (1987).

Kanda, K., T. TanaKa and K. SobUe: Calspectin (fodrin or nonerythroid spectrin)-actin interaction: a possible involvement of 4.1-related protein. Biochem. Biophys. Res. Commun. 140: 1051-1058 (1986).

Levine, J. and M. WiLlaRd: Fodrin: axonally transported polypeptides associated with the internal periphery of many cells. J. Cell Biol. 90: 631-643 (1981).

OKABE, T. and K. SobUE: Identification of a new 84/82 $\mathrm{kDa}$ calmodulin-binding protein, which also interacts with actin filaments, tubulin and spectrin, as synapsin I. FEBS Lett. 213: 184-188 (1987).
SAuer, F. C.: Mitosis in the neural tube. J. Comp. Neurol. 62: 377-405 (1935).

Senda, T. and H. FuJITA: Ultrastructural aspects of quick-freezing deep-etching replica images of the cytoskeletal system in anterior pituitary secretory cells of rats and mice. Arch. Histol. Jap. 50: 49-60 (1987).

Shimo-oka, T. and S. Atsumi: Localization of $\alpha$-spectrin in chicken and monkey ventral horns by immunoelectron microscopy. J. Neurocytol. 15: 715-723 (1986).

Shiomura Y. and N. Hirokawa: Colocalization of microtubule-associated protein $1 \mathrm{~A}$ and microtubuleassociated protein 2 on neuronal microtubules in situ revealed with double-label immunoelectron microscopy. J. Cell Biol. 104: 1575-1578 (1987).

SobUE, K., K. KANDA and S. KAKIUCHI: Solubilization and partial purification of protein kinase systems from brain membranes that phosphorylate calspectin. A spectrin-like calmodulin-binding protein (fodrin). FEBS Lett. 150: 185-190 (1982).

Sobue, K., T. OKabe, K. KadowakI, K. ITOH, T. TanaKa and Y. FUJı: Cytosynalin: A Mr 35,000 cytoskeletoninteracting and calmodulin-binding protein. Proc. Nat. Acad. Sci. USA 84: 1916-1920 (1987). 